\title{
RESEARCH
}

\section{Death and Destitution: The Global Distribution of Welfare Losses from the COVID-19 Pandemic}

\author{
Francisco H. G. Ferreira1, Olivier Sterck², Daniel G. Mahler ${ }^{3}$ and Benoît Decerf ${ }^{3}$ \\ 1 London School of Economics and IZA, GB \\ 2 University of Oxford, GB \\ 3 World Bank, US \\ Corresponding author: Francisco H. G. Ferreira (f.d.ferreira@lse.ac.uk)
}

\begin{abstract}
The Covid-19 pandemic has brought about massive declines in wellbeing around the world. This paper seeks to quantify and compare two important components of those losses - increased mortality and higher poverty - using years of human life as a common metric. We estimate that almost 20 million lifeyears were lost to Covid-19 by December 2020. Over the same period and by the most conservative definition, over 120 million additional years were spent in poverty because of the pandemic. The mortality burden, whether estimated in lives or in years of life lost, increases sharply with GDP per capita. The poverty burden, on the contrary, declines with per capita national incomes when a constant absolute poverty line is used, or is uncorrelated with national incomes when a more relative approach is taken to poverty lines. In both cases the poverty burden of the pandemic, relative to the mortality burden, is much higher for poor countries. The distribution of aggregate welfare losses - combining mortality and poverty and expressed in terms of life-years - depends both on the choice of poverty line(s) and on the relative weights placed on mortality and poverty. With a constant absolute poverty line and a relatively low welfare weight on mortality, poorer countries are found to bear a greater welfare loss from the pandemic. When poverty lines are set differently for poor, middle and high-income countries and/or a greater welfare weight is placed on mortality, upper-middle and rich countries suffer the most.
\end{abstract}

Keywords: COVID-19; pandemic; welfare; poverty; mortality; global distribution

\section{Introduction}

Since its onset in December 2019, the Covid-19 pandemic has spread death and disease across the whole world. Around the time of its "first anniversary", on 15 December 2020, 1.64 million people were counted as having lost their lives to the virus globally and, ${ }^{1}$ because of the likelihood of under-reporting, that was almost certainly an undercount. Although it is primarily a health crisis - with substantial additional pain and suffering caused to the tens of millions who have survived severe cases of the disease and, in many cases, continue to suffer from its long-term ill-effects - the pandemic has also had major economic effects. The current estimate is that global GDP per capita declined by $5.3 \%$ in 2020. Economic contraction was widespread, with 172 out of the 182 countries for which data is available experiencing negative growth in real GDP per capita in 2020 (World Bank [1]).

This severe global economic shock has caused the first reversal in the declining trend in global extreme poverty (measured as the share of the world's population living under \$1.90 per day) since the Asian Financial Crisis of 1997 - and only the second real increase in world poverty since measurement began in the early 1980s. ${ }^{2}$ This increase in extreme deprivation comes with its own suffering and anguish: jobs and homes were lost and people struggled to feed their children and themselves. Many asked whether they "would die of Coronavirus or hunger?"3

\footnotetext{
${ }^{1}$ Our World in Data, https://ourworldindata.org/grapher/cumulative-covid-deaths-region.

${ }^{2}$ There was also an apparent increase in 1989, which is fully accounted for by China switching from an income to a consumption indicator. See https://data.worldbank.org/indicator/SI.POV.DDAY.

${ }^{3}$ On 11 February 2021 a Google search for "dying of coronavirus or hunger" yielded 2,330,000 results. Some of the titles on the first page included "The pandemic pushes hundreds of millions of people toward starvation and poverty" (Washington Post, 25 September 2020) and "More people may die from hunger than from the Coronavirus this year..." (Forbes, 9 July 2020).
} 
This paper seeks to address two questions. First, what were the relative contributions of increased mortality and poverty to the welfare losses caused by the pandemic, and did these contributions vary systematically across countries? Second, how were the aggregate welfare losses distributed across countries? ${ }^{4}$

We look at the impact on the cross-country distribution of wellbeing with the recognition that both the health crisis and the economic debacle have caused huge welfare losses. We focus on extreme outcomes in both domains: mortality in the case of health and falling into poverty in the case of economics. This implies that our estimates of welfare losses are clearly a lower-bound: we ignore the burden of the disease on those who survive it and, furthermore, data limitations mean that we look only at deaths officially classified as due to Covid, rather than the possibly preferable metric of excess deaths. ${ }^{5}$ Similarly, we ignore welfare losses from income declines that do not entail entry into poverty and, furthermore, we look only at the short-term poverty consequences arising from the contemporaneous income losses in 2020 . We ignore, therefore, the longer-term consequences of any harms to child development arising from additional undernutrition, or the likely substantial future consequences of the schooling crisis that resulted from the pandemic (see, e.g., Lustig et al. [2]). These choices are not intended to minimize the importance of those negative consequences of the pandemic. On the contrary, the evidence to date suggests that they will be extremely important. Rather, they follow from a desire to focus on the most severe short-term consequences of the crisis along the two principal dimensions of health and incomes, using the best available data while avoiding an accumulation of assumptions and simulations. We are forced to make some assumptions to fill data gaps that inevitably arise when analysing an ongoing phenomenon, but they are few, and therefore are hopefully clearer and more transparent than if we had tried to incorporate expected future losses, and so on.

A welfare-based approach requires comparing health and income losses or, in our case, mortality and poverty costs. As in Decerf et al. [3], we eschew more traditional methods such as the valuation of statistical life (VSL, see e.g. Viscusi [4]). Our approach is theoretically closer to the modeling of social welfare as aggregate expected lifetime utility, as in Becker et al. [5] or Adler et al. [6]. But, unlike those authors, we model the effect of the pandemic on social welfare in a way that allows us to use years of human life - either lost to premature mortality or spent in poverty - as our unit of comparison. This has two advantages over the alternative of using a money metric to value human lives: first, we hope it overcomes the instinctive aversion of many participants in the public debate to the idea of placing a "price" on human life. Second, the model yields a single, easily understandable normative parameter for the trade-off between mortality and poverty which has a direct, observable empirical counterpart. We can then simply present the empirical object for all countries in our sample, and let the reader compare her own valuation of the normative parameter to the data.

The simple model is presented in Decerf et al. [3], and we do not repeat it here. The basic ingredients are (1) a utilitarian welfare function that simply adds up lifetime individual utility across people and time periods; ; $(2)$ an individual utility function that depends solely on whether one is dead, poor or non-poor; ; and (3) an assumption that the pandemic may have two effects on people: it may (or may not) cause them to die earlier than they otherwise would, and it may (or may not) cause them to spend some more time in poverty before they die, relative to the counterfactual. This simple framework yields the result that the overall welfare effect of the pandemic is proportional to a weighted sum of the number of years of life lost to premature (Covid-induced) mortality and the number of additional years spent in poverty. The relevant equation is:

$$
\frac{\Delta W}{\Delta u_{p}}=\alpha L Y+P Y
$$

In Equation (1) $\Delta W$ denotes the expected impact of the pandemic on social welfare; $\Delta u_{p}$ is the difference in yearly individual well-being between being poor and non-poor; and $L Y$ and $P Y$ are respectively the total number of years of life lost and the total number of additional years spent in poverty due to the pandemic. $\alpha$ is a normative parameter that represents the ratio between the individual utility loss from each year lost to premature mortality $\left(\Delta u_{d}\right)$ and the loss from each additional year spent in poverty $\left(\Delta u_{p}\right) \cdot \alpha$ is therefore the (social) marginal rate of substitution between life- and poverty-years. It can be understood as the "shadow price" of a lost life-year, expressed in terms of poverty years. Concretely, one can think of it as the answer people might give to the following hypothetical question: "If you could make this bargain, how many years would you be willing to spend in poverty during the rest of your life in order to add one additional year at the end of your life?"

Clearly, there is plenty of room for individual disagreement about the answer to that question, and so about the value of $\alpha$. Different people might answer that question very differently, depending on how far above the poverty line they are (or expect to be); on their expected residual life-expectancy and, of course, on their preferences. We thus choose to remain mostly agnostic about $\alpha$. In what follows, we simply present values for LY and PY across as many countries as

\footnotetext{
${ }^{4}$ To answer these questions, we revisit and update some of our earlier findings in Decerf et al. [3]. In that earlier paper we did not address the second question above and, conversely, we do not explore counterfactual herd immunity scenarios here, as we did there. The first question above was also addressed in the earlier article using mortality and poverty estimates from June 2020, but here are updated to December 2020.

${ }^{5}$ Even if data on excess mortality were more widely available it would also include additional deaths caused by poverty, potentially confounding our comparisons.

${ }^{6}$ With no aversion to inequality and no time discounting.

${ }^{7}$ Simple restrictions imply that this is a step-function approximation to utility that is increasing and concave in incomes, but the coarseness we introduce means that people are insensitive to income gains or losses that do not entail a crossing of the poverty line. This simplification may be seen as the price we pay for converting to a life-year metric, but it is also consistent with our emphasis - discussed above - on the extreme outcomes of death and destitution (defined as falling into poverty).
} 
possible. When we discuss the relative contributions of mortality and poverty, we present ratios of PY to LY, which the reader can compare to her own preferred value for $\alpha$ in order to assess which source is responsible for the larger welfare loss. Next, when we seek to summarize the inter-country distribution of welfare losses, we suggest a plausible range for $\alpha$ : between five and twenty years.

The rest of this short paper is organized as follows. The next section describes how we compute the numbers of years of life lost (LY) and additional poverty years (PY) for each country, given the available data, and presents the estimates for 145 countries. Building on those ingredients, Section 3 summarizes the evidence on the relative importance of poverty and mortality in lowering welfare around the world. It also investigates the global distribution of those losses under plausible values for the key normative parameter, both for a constant absolute poverty line and under a more relativist approach to poverty identification. Section 4 concludes.

\section{Estimating additional mortality and poverty with imperfect data}

To compute the total number of years of life lost to the pandemic in each country, we first estimate how long each person reported as having died of COVID-19 in that country until 15 December 2020 might have lived, had the pandemic not occurred. That quantity is obviously not observed: it is a counterfactual. We use each country's pre-pandemic residual life expectancy at the age of the person's death as our estimate of that counterfactual. A country's residual life expectancy at age $a$ is given by how much longer the average person who reaches that age in that country tends to live (pre-pandemic). It can be calculated from data on population pyramids from the UN Population Division database.

Once we have estimates of the residual life expectancy at each age for each country, the total number of years of life lost in each country is simply the sum across all ages of the number of COVID-19 deaths at each age times the residual life expectancy at that age. Data on the number of COVID-19 deaths at each age can be obtained directly for some countries but it is not publicly available for all of them. Where it is not available, we estimate it using data on aggregate COVID-19 fatalities and on age-specific infection-fatality rates for certain countries. Those data are fortunately available for many countries from the Global Burden of Disease Database (Dicker et al. [7]) and from other sources. Appendix 1 provides details of those sources and of the exact procedure we use to generate our LY estimates for 145 countries.

Using this method, we estimate that Covid-induced mortality in the year to 15 December 2020 caused the loss of 19.3 million years of life across the 145 countries in our sample (which account for $96 \%$ of the world's population). Absolute numbers range from 14 years lost in Burundi to 3,148,000 in the United States. ${ }^{8}$ Those aggregates numbers obviously depend a great deal on the country's population. Figure 1 below plots life years lost adjusted by population (LY per 100,000 people) against each country's GDP per capita, with both axes in logarithmic scale.

Two features of the scatter plot are worth highlighting: First there is enormous variation in the population-adjusted loss of life-years across countries. Even if one discounts Burundi and Tanzania as outliers where reporting is unlikely

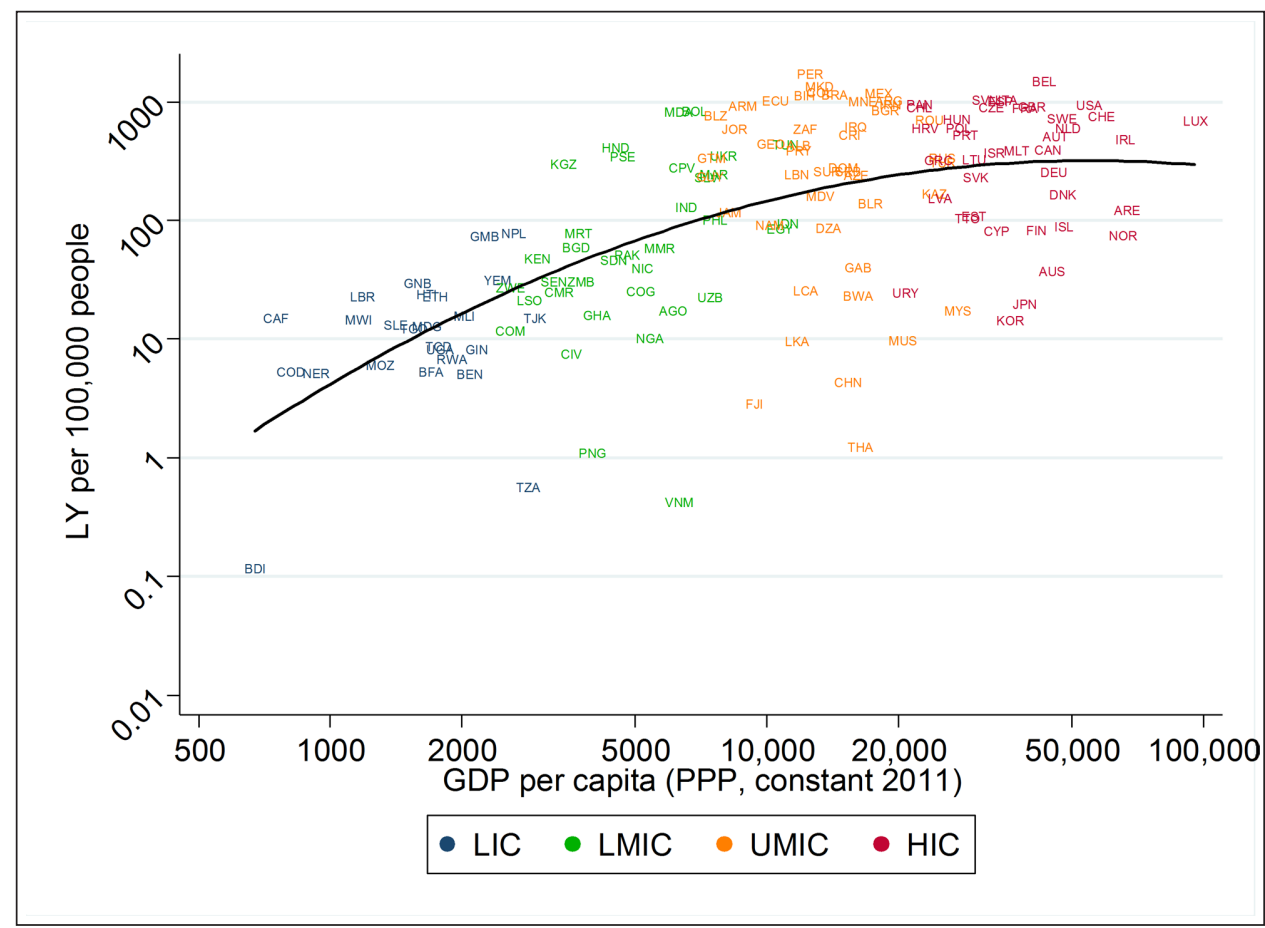

Figure 1: Life-years lost to Covid, and GDP per capita.

\footnotetext{
${ }^{8}$ Measurement error is likely to plague a number of these country estimates, with under-reporting being of particular concern. Deaton [8] singles out Burundi and Tanzania as likely candidates for under-reporting.
} 
to have been reliable, LYs range from roughly one year lost per 100,000 people (in countries as diverse as Papua New Guinea, Thailand and Vietnam) to one or more years lost per 100 people, in a large set of countries including Brazil, Peru, Mexico, Belgium, the Czech Republic and the United States. Some of that variation is systematic: Figure 1 reveals a strongly positive (and concave) ${ }^{9}$ relationship between the mortality costs of Covid and level of economic development. ${ }^{10}$ Second, however, there is also considerable variation around the regression line at each income level - particularly at and above per capita GDP levels of \$5,000 or thereabouts: Brazil and Thailand have comparable per capita income levels, but Brazil lost roughly one thousand life-years for each life-year lost in Thailand, controlling for population. The disparity is even greater between Bolivia and Vietnam, and still striking between France and South Korea.

What explains this massive variation in population-adjusted life-years lost to Covid - both across and within countryincome categories? Mechanically, it must reflect cross-country differences in three variables: the age structure of the population; residual life-expectancies at each age; and age-specific mortality rates. ${ }^{11}$ The first two are slow-moving variables that reflect each country's historical development; the stage of the demographic transition they are in; the ease of access to and the quality of their health care systems, etc.

The last variable - the country's age-specific mortality rates, which are themselves the product of infection rates and infection fatality rates (Eq. A3 in Appendix 1) - reflects each country's exposure and response to the pandemic. Infection rates, (which vary substantially internationally) initially reflected how quickly the virus arrived in each country, and then the extent to which health systems were able to prevent spread within the country. Infection rates are also likely to depend on urbanization and climate. Infection-fatality rates reflect the quality of health care and the extent to which, for example, hospitals were overwhelmed by the pandemic at any stage.

Our data suggests that all three of these variables contribute to the positive association between the populationadjusted mortality burden of the pandemic and national per capita income seen in Figure 1. It is well-know that Covid mortality varies substantially with age, and that it is much higher for the elderly. Figure A1 in Appendix 2 plots the ratio of Covid mortality among those aged 65 and over to the mortality among 20-39 year-olds in our data: the ratio ranges from around 100 in low and middle-income countries to between 200 and 300 among high-income countries. ${ }^{12}$

Figures A2 and A3, also in Appendix 2, plot indicators for the other two variables, namely the age structure of the population and age-specific residual life expectancies, both against per capita GDP. Specifically, Figure A2 plots the share of the population aged 65 or over (which ranges from 3-4\% among the poorest countries to 20-25\% among some of the richest); and Figure A3 looks at the residual life expectancy at age 65 across countries - which ranges from 13-15 years among most low-income countries (LICs) to 20-23 at the high-end, mostly among high-income countries (HICs). These upward sloping curves in Figures A1 - A3 suggest that all three variables play some role in contributing to the positive slope in Figure 1. Covid mortality is highly selective on age; richer countries have many more people in the vulnerable, elderly age ranges; and they tend to have higher life-expectancies at those ages, implying a larger number of years lost per death.

Turning to the estimates of poverty years added by the Covid pandemic, it is important to note, first of all, that the household surveys from which we generally obtain reasonably reliable estimates of poverty are not yet available for 2020 in any country. This means that actual data on household incomes or consumption levels are not available at this time, and one must rely on ex-ante estimates and approximations.

In that context, our basic approach is to compare "expected" poverty rates in 2020 under two scenarios: one with Covid and one without. To do this, we use the remarkable collection of household survey microdata from 166 countries contained in the World Bank's PovcalNet database..$^{13}$ The dates of the latest household surveys in that database vary across countries, but all are "aligned" to 2019, using historically documented growth rates in GDP per capita and a passthrough coefficient to adjust for the fact that growth in mean incomes in household surveys is typically less than GDP per capita growth measured in the National Accounts. ${ }^{14}$ This procedure, which is carried out internally at the World Bank for nowcasting poverty, assumes no change in inequality between the last available household survey and 2019.

Our starting point are these distributions of household per capita income or consumption, expressed in US dollars at PPP exchange rates, aligned for the pre-Covid year of 2019. From these distributions, one can calculate the headcount measure of poverty in each country in 2019 (for any given poverty line $z$ expressed in per capita terms) simply as the share of the population with incomes below that line. We then obtain our estimate of poverty in the counterfactual "noCovid 2020" scenario by applying the (adjusted) growth rate forecast for 2020 in the January 2020 issue of the Global

\footnotetext{
${ }^{9}$ An increasing and concave function - or relationship - is one that increases at a decreasing rate.

10 Deaton [8] presents a similar figure that plots the log of lives - rather than life-years - lost against log GDP per capita. He notes that "there is no relationship [...] within the OECD." Goldberg and Reed [9] also document that, as of July 2020, the number of lives lost to Covid per million inhabitants was larger in advanced economies than in developing countries. They suggest that older populations and a greater prevalence of obesity in developed countries can partially explain this positive association between mortality and development.

11 See Equation A1 in Appendix 1.

12 Some of actual variation in this ratio is missing because age-specific mortality data is, as discussed in Appendix 1 , not widely available, so we use France's IFR for all HICs, and China's for all other countries. This accounts for the sharp jump between MICs and HICs in Figure A1.

13 We use data from 145 of these 166 countries, for which we can find the required mortality statistics.

14 It is assumed that 85 percent of growth in GDP per capita is passed through to growth in welfare observed in household surveys in line with historical evidence (Lakner et al. [10]).
} 
Economics Prospect (GEP) to each country's 2019 income distribution. Analogously, the poverty estimate for the 2020 Covid scenario is obtained by applying to the same 2019 income distributions the (adjusted) growth rate forecast for 2020 in the October 2020 Macro and Poverty Outlook report of the World Bank. ${ }^{15}$

The idea, of course, is that the January forecasts were produced at a time when Covid-19 was a little heard-of virus confined to Wuhan province in China, and no macroeconomist had remotely imagined a pandemic on the scale we have since seen. The October forecasts, on the other hand, were the latest available for 2020 at the time of writing and reflect the World Bank's expectations of the pandemic's impact on growth around the world. Finally, we assume - conservatively - that the short-run poverty effect of the pandemic lasts for a single year, so that each additional person in poverty corresponds to precisely one additional poverty year. The total number of additional poverty years generated by the pandemic is then given simply by the difference between the poverty estimates for 2020 under the Covid and the non-Covid scenarios.

Naturally, the number of poverty-years added by the pandemic depends on the poverty line that is used. Figure $\mathbf{2}$ below presents two of many possible poverty line options: Panel A uses a constant absolute line for all countries, namely the World Bank's international (extreme) poverty line of \$1.90 per person per day (Ferreira et al. [12]). While there are good reasons for using the same poverty line in an international comparison of this kind, there are equally valid arguments for attempting to account for the fact that basic needs themselves may vary with national income, and that a different (and costlier) bundle of commodities may be needed to achieve the same welfare (or capabilities) threshold in Austria, say, than in Afghanistan. This latter view implies that "poverty" means different things (at least in income terms) in countries where average incomes are vastly different, and often leads to the adoption of relative or weakly-relative poverty lines (see, e.g. Atkinson and Bourguignon [13], and Ravallion and Chen [14]). ${ }^{16}$

Panel B of Figure 2 adopts a (coarse) approximation to a relative poverty line: It uses the World Bank's income-class poverty lines proposed by Jolliffe and Prydz [15]. Using a database of contemporaneous national poverty lines in 126 economies, these authors selected the median values of per capita poverty lines among low-income countries (\$1.90); lower middle-income countries (\$3.20); upper middle-income countries (\$5.50); and high-income countries (\$21.70). In Panel B, poverty years are computed using these income-class specific poverty lines for countries in each income category.

Using the \$1.90 line for all countries, we estimate that a total of 121 million additional poverty years were induced by Covid-19 in the year to 15 December 2020 across the 145 countries in our sample. Absolute numbers range from $-35,800$ in Papua New Guinea ${ }^{17}$ to 74.2 million in India. Panel A in Figure 2 reveals - perhaps unsurprisingly - a strongly downward-sloping relationship with GDP per capita, with an average of 2,568 poverty years per 100,000 people added in low-income countries, as compared to 28.5 years per 100,000 people added in high-income countries.

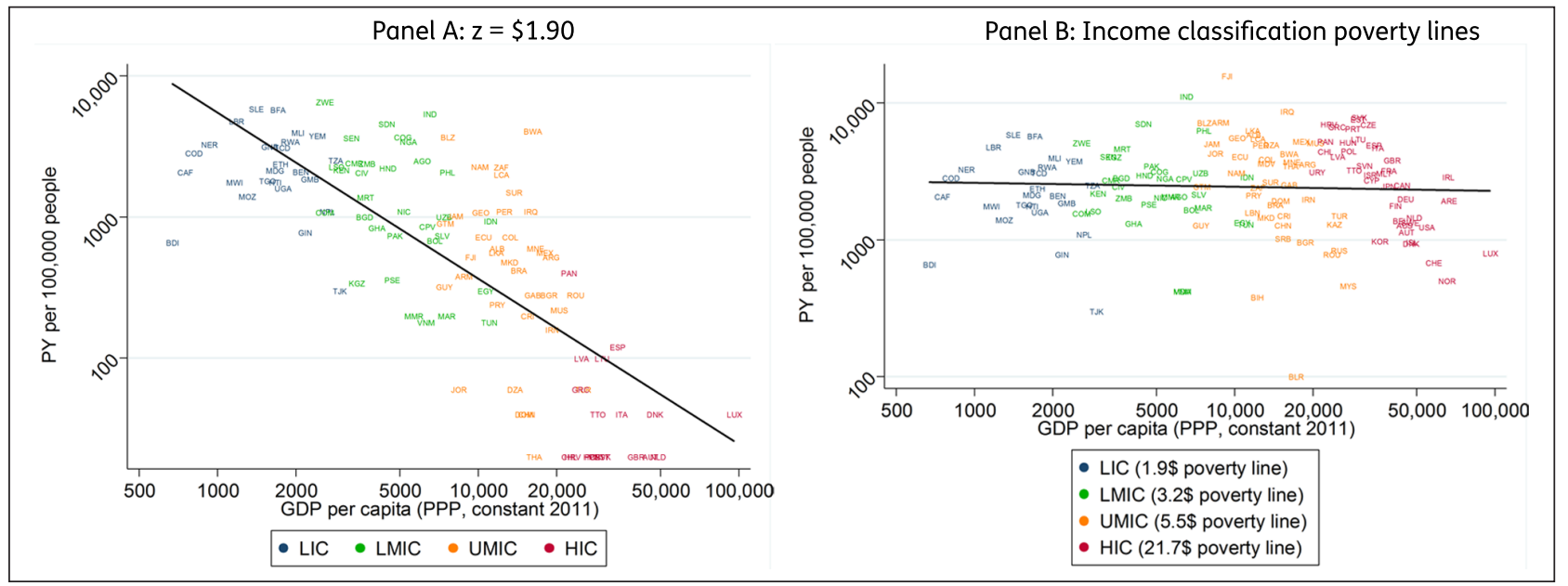

Figure 2: Poverty-years added by Covid, and GDP per capita.

\footnotetext{
15 This method assumes that the adjusted growth rates in real GDP per capita accurately reflect the growth (or shrinkage) in household consumption. With ongoing globalization, the importance of tax havens, and so on, one might imagine that GDP has further decoupled from household consumption and that other variables from national accounts-or other economic indicators altogether-could be more informative. Yet Castaneda et al. [11] show that, out of more than a thousand variables, the change in real GDP per capita is the second most predictive variable of changes in household consumption. The only variable that does better is changes in employment, for which we do not have pre- and post-COVID forecasts for 2020 that are widely comparable across a large number of countries.

16 Note that this argument is unrelated to differences in prices, which are supposed to be addressed by the use of PPP exchange rates.

17 Papua New Guinea is the only country for which the October 2020 growth forecast for 2020 was higher than the January 2020 forecast.
} 
The negative slope disappears completely in Panel B, where median poverty lines from each country income category (from low- to high-income) are used for countries in the respective groups. The slope of the linear regression line across the entire scatterplot is not significantly different from zero. ${ }^{18}$ The mean number of PYs/100,000 people is 2,568 for low-income countries, 2,778 for lower middle-income countries, 3,418 for upper middle-income countries and 3,330 for high-income countries. It is perhaps worth noting that there is nothing mechanical about this particular result: there is no reason why one would necessarily expect that adopting median poverty lines among groups of progressively richer countries would completely eliminate the negative association between the poverty burden of the pandemic and GDP per capita. Using these more generous poverty lines, our estimate for the total number of additional poverty years induced by the pandemic rises to 300 million.

The next section seeks to combine the country-level PY and LY estimates obtained above in order to assess their relative and absolute importance in determining overall welfare losses from the pandemic.

\section{Total welfare losses and the relative contributions of death and destitution}

Given the estimates of life-years lost to and of poverty-years added by the pandemic, we now ask: first, which of the two sources contributed the most to lowering welfare in each country; and second, what were those total welfare costs, using our metric of poverty years. The answers to both questions depend critically on the value of $\alpha$, the normative parameter that tells us how many PYs cause as great a welfare loss as a single LY. Given a value of $\alpha$ and the ratio of PYs to LYs observed in any particular country, we can immediately tell whether poverty or mortality contributed the most to the aggregate welfare losses from the pandemic in that country. Wherever the actual ratio of PYs to LYs exceeds the reader's chosen value for $\alpha$, poverty is the greater source of welfare loss: the country added more poverty years for each lost life year than the reader thinks a life year is "worth" in terms of poverty years. Conversely, if the actual ratio is lower than $\alpha$, then mortality was the greater contributor to falling well-being. ${ }^{19}$

Figure 3 plots those observed ratios against GDP per capita for all countries in our sample, using the income-class specific poverty lines used in Panel B of Figure 2. (The line is even steeper if the constant \$1.90 line were used instead.) Two things are immediately apparent: first, the variation in empirical PY/LY ratios is enormous: the median ratio is 15.7 (in United Arab Emirates) and the range is from 0.33 (in Bosnia and Herzegovina) to 5537 (in Burundi). ${ }^{20}$ Second, the poverty to life-years ratio is strongly negatively correlated with GDP per capita: although the regression lines shown in

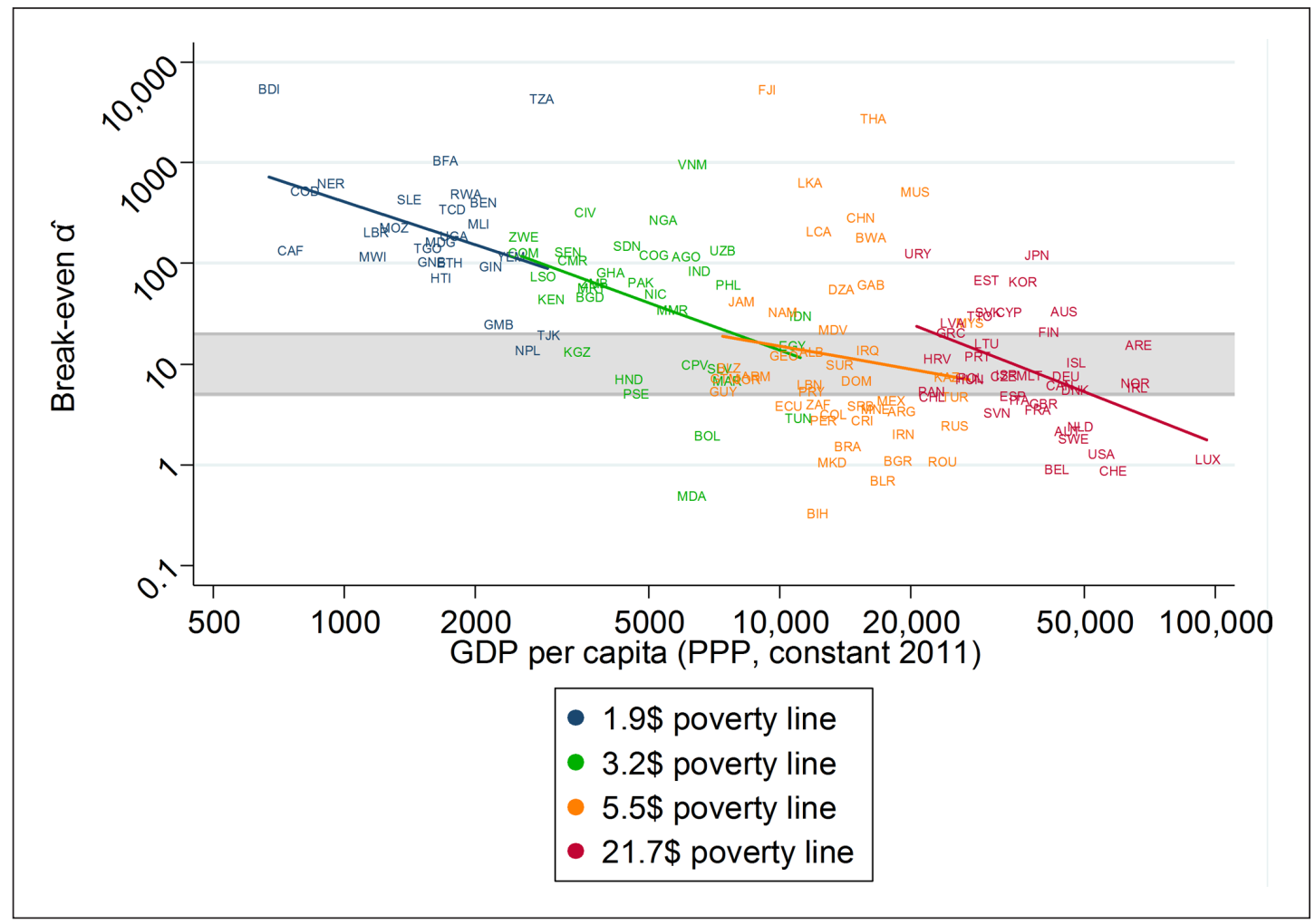

Figure 3: PY/LY ratios and GDP per capita.

\footnotetext{
18 The slope is -0.0286 , with a p-value of 0.612 .

${ }^{19}$ A little more formally: if we denote the empirical ratio by $\hat{\alpha}_{j}=P Y_{j} / L Y_{j}$, then an observer with an such $\alpha$ that $\hat{\alpha}_{j}>\alpha$ will regard poverty as the principal source of welfare loss in country $j$. Conversely, if $\hat{\alpha}<\alpha$, then mortality is considered the greatest source of welfare loss.

20 Looking only at positive values, and thus excluding Papua New Guinea (see previous footnote) and Azerbaijan (zero PYs reported).
} 
Figure 3 are for each income class, a simple linear regression over the entire sample has a highly significant negative slope. ${ }^{21}$

So far, we have been entirely agnostic about the value of $\alpha$. Indeed, we argue that one advantage of our approach is that it can encapsulate the normatively challenging trade-off between lives and livelihoods in a single, easily interpretable parameter, while simultaneously remaining agnostic about its value. In order to make further progress in interpreting Figure 3, however, it will prove helpful to suggest a "plausible range" for $\alpha$, which we set at $5 \leq \alpha \leq 20$. In terms of the question we proposed earlier as a means to elicit the normative judgement, this range means that most people in a country value an additional year of life-expectancy as being worth spending at least an additional five years, and at most an additional twenty years, in poverty.

We do not yet have robust empirical evidence from surveys or experiments that try to elicit empirical values of $\alpha$, so the reader may of course pick a value completely outside that range. ${ }^{22}$ But those who are comfortable with such a range could, on inspection of Figure 3, classify countries into three broad groups. Those below the band of grey shadow $(P Y / L Y \leq 5)$ are countries where the social welfare cost of the pandemic until December 2020 arose primarily from additional mortality, rather than from increases in poverty. This group includes a wide variety of nations, such as Bolivia, Brazil, Russia, Belgium and the US. The most extreme cases are Moldova, Bosnia and Herzegovina and Belarus where the ratio PY/LY is below even the theoretical lower bound of one for $\alpha$. Belgium and the Czech Republic are close behind. This first group consists primarily of upper-middle and high-income countries and does not include a single low-income country.

A second group consists of those above the band of grey shadow in the Figure $(P Y / L Y \geq 20)$. In these countries, increased destitution contributed more to declining social welfare than deaths and the loss of life years they caused. There are 70 countries in this group, including most low- and lower middle-income countries. This group also includes most countries frequently identified in the popular media as successful in combating the pandemic, through early lockdowns strictly enforced and/or well-functioning testing and tracing systems, such as Australia, China, Japan, Korea and Vietnam. Uruguay is the only continental Latin American country in this group, while its neighbours Argentina and Brazil (as well as Chile) are in Group 1 above. ${ }^{23}$

The third group consists of those countries in the grey band, whose empirical PY/LY ratios fall within our "plausible range" for $\alpha$ : between 5 and 20. Given that range, we are unable or unwilling to select either poverty or mortality as the main culprit in lowering social welfare in these countries. In other words, these are countries where their relative contributions were broadly similar. The group includes countries from every income category, from Nepal at the poorer end to Norway and the United Arab Emirates at the richer end. But Nepal and Tajikistan are the only two low-income countries in the group; all other LICs are in Group 2, where poverty dominated mortality as a source of declining wellbeing from the pandemic.

Can we go beyond the relative contributions of mortality and poverty in each country and compute the aggregate welfare losses from the pandemic (arising both from deaths and additional destitution) in each country? Strictly speaking, of course, we suffer from the usual problem of choosing a suitable unit for measuring well-being. But if we are willing to abstract from measures of individual utility, Equation (1) tells us that the change in welfare in a country is proportional to the weighted sum of the number of years of life lost to and poverty years added by the pandemic, with the weight on life-years given by $\alpha: \alpha L Y+P Y$. Using the sum, as we do below, corresponds to using additional years spent in poverty as our social welfare metric.

Of course, computing that weighted sum requires - once again - choosing both an approach to poverty identification (one or more poverty lines) as well as one or a range of values for $\alpha$. For consistency, we use the same two sets of poverty lines used in Figure 2 (a constant line of \$1.90, and the set of four income-classification poverty lines). For $\alpha$ we pick the bounds of our guidance range, namely $\alpha=5$ and $\alpha=20$. Figure 4 below plots aggregate social welfare losses, $\alpha L Y$ $+P Y$, against GDP per capita for all 145 countries in our sample: The first row (Panels A and B) uses the constant poverty line of \$1.90: Panel A uses $\alpha=5$ and Panel B uses $\alpha=20$. The second line (Panels C and D) uses the income-classification poverty lines: once again with $\alpha=5$ in Panel C and $\alpha=20$ in Panel D. To control for population sizes, in all cases the welfare costs are expressed per 100,000 people.

As expected, there is a great deal of cross-country variation in the welfare burden of the pandemic, regardless of which panel one looks at. The unit of measurement along the $y$-axis, as noted earlier, is additional person-years spent in poverty per 100,000 people. In panel $\mathrm{A}$, using the most stringent global poverty line ( $\$ 1.90$ per person per day) and a relatively low value of $\alpha$, the burden ranges from 26 in Thailand and 62 in China, to 7,556 in Belgium and 9,811 in Peru. The regression line across the scatter of countries in Panel A is downward sloping and that negative slope (-0.14) is statistically significant $(\mathrm{p}=0.036)$, indicating a negative association between national income and the aggregate welfare losses from the deaths and destitution caused by the pandemic. Given the strong positive association between the mortality burden and GDP per capita seen in Figure 1, this is an important finding: the pandemic appears to have

\footnotetext{
21 The slope is -1.043 (p-value $=0.000)$.

22 Preliminary results from surveys we have conducted in the US, UK and South Africa suggest very low values for $\alpha$. The mean across the three samples was 2.6. Work on these surveys is ongoing, and these early results are tentative and should be treated with caution. Nonetheless, they suggest that, if anything, our plausible range for $\alpha$ is on the high side, which would lead the results that follow to place "too much" weight on mortality, relative to poverty.

${ }^{23}$ In the Caribbean, Jamaica, St. Lucia and Trinidad and Tobago are also in Group 2.
} 


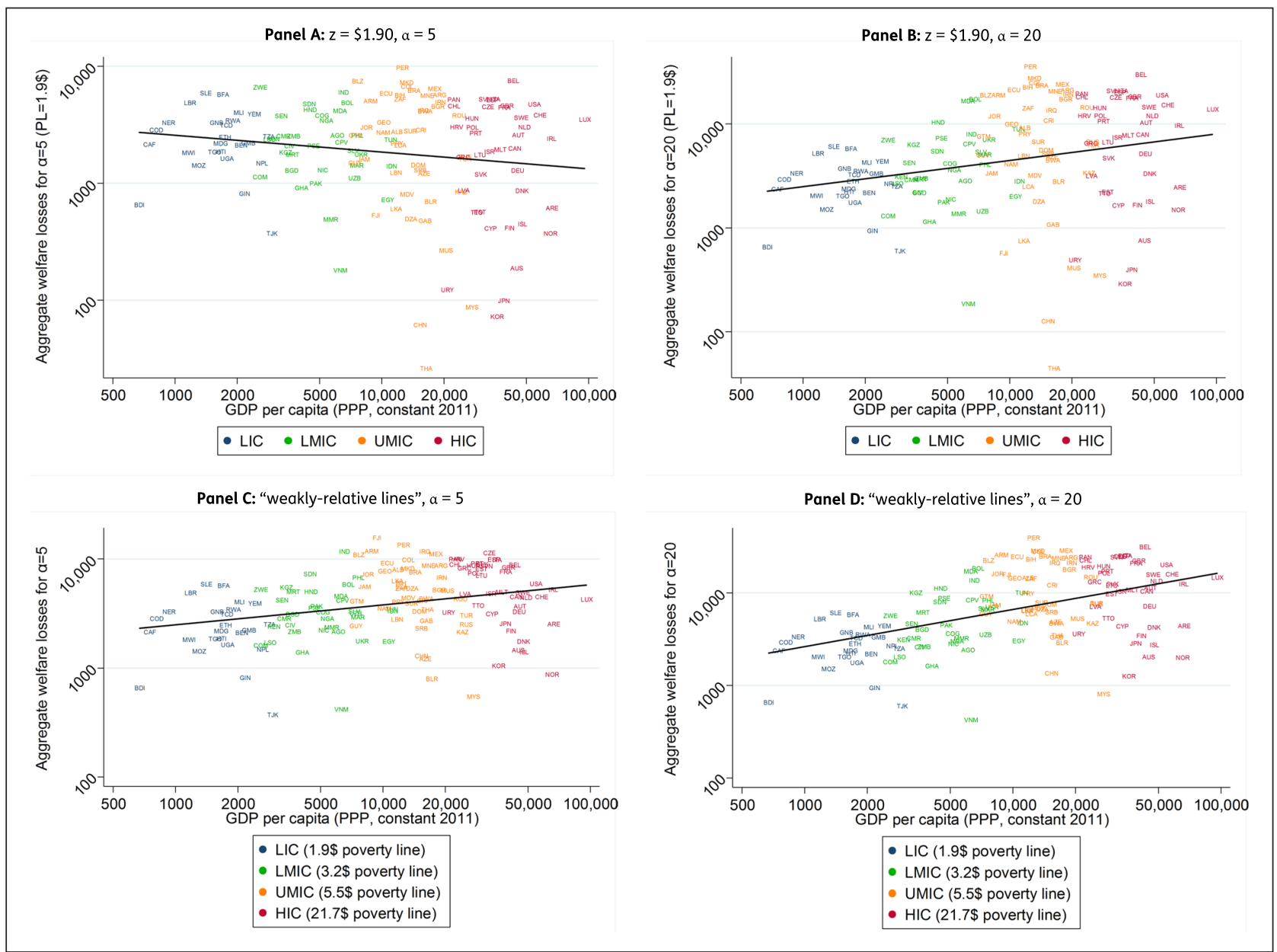

Figure 4: Total welfare losses from the pandemic, and GDP per capita.

induced such large increases in extreme poverty in poor countries (Figure 2A) that the combined burden of poverty and mortality is, on average, greater for them than for richer countries. ${ }^{24}$

The pattern changes (and the overall numbers are mechanically higher) in Panel B, where each life-year lost is counted as being equivalent to 20 , rather than 5 , added poverty-years. The association with GDP per capita now becomes positive and statistically significant, because mortality was much higher in richer countries.

Panels $C$ and $D$ would be preferred by those who take a more relative view of poverty. They use poverty lines that are typical of countries in their income ranges: $\$ 1.90$ for low-income countries; $\$ 3.20$ for lower middle-income countries; $\$ 5.50$ for upper middle-income countries; and $\$ 21.70$ for high-income countries. Naturally, this raises the number of poverty years in all but the low-income countries, and the positive slope of the relationship with GDP per capita strengthens further, first with $\alpha=5$, and even more with $\alpha=20$. Using more demanding poverty lines in upper middle-income countries means that ranks change at the bottom, with Tajikistan and Vietnam now reporting the lowest welfare burdens in the world, at 376 and 422 years per 100,000 people respectively (with $\alpha=5$ ). Fiji $(15,855)$ and Peru $(13,631)$ now occupy the top ranks in the distribution of population-adjusted welfare losses.

Figure 4 tells us that whether total welfare losses (from deaths and short-term increases in poverty) are deemed to rise or fall with national income per capita depends on how one chooses to define and compare poverty across countries, and on the relative welfare weight between mortality and poverty. When one takes a more relative view of poverty, allowing for the fact that different (more expensive) bundles of goods are needed to escape poverty in richer countries, then the impact of the pandemic on poverty is uncorrelated with per capita income (Figure 2B). Since mortality is strongly correlated with income, this implies that overall losses are greater in richer than in poorer countries on average. This is still true even if a constant extreme poverty line is used, provided the welfare weight of mortality relative to poverty is high enough (Figure $\mathbf{4 B}$ ).

The positive association in Figure 4B, C and $D$ is clearly related to Deaton's [8] finding that the effect of the pandemic on economic growth was negatively associated with GDP per capita - that is: on average, richer countries experienced

\footnotetext{
${ }^{24}$ Yet, there is so much variation around the regression line that, even with this parameter configuration, the greatest losses in welfare were recorded in upper middle-income countries such as Belize, Macedonia and Peru, alongside rich countries like Belgium. But poorer countries such as Burkina Faso, Sierra Leone and Zimbabwe are not far behind.
} 
larger proportional declines in real national income (as well as more deaths per capita). ${ }^{25}$ But, as the author was careful to point out, his "results say nothing about whether the degree of suffering has been larger of smaller in poor countries" [8, p4]. Our results are also far from capturing all the suffering caused by the pandemic: as discussed earlier, disutility from ill health among survivors and losses from increased malnutrition or paused schooling are ignored, among other things. Nonetheless, if one takes falling into extreme poverty (relative to the \$1.90 line) as an indication of absolute economic suffering, our results suggest that the positive association can be reversed - provided the weight placed on that kind of destitution is high relative to mortality.

\section{Conclusions}

In this paper we have sought to address two sets of questions: First, what were the relative contributions of increased mortality and poverty to the welfare losses caused by the pandemic, and did those contributions vary systematically across countries? Second, how large were the aggregate welfare losses, and how were they distributed across countries? We focused on welfare losses caused by extreme outcomes along both the health and income dimensions: death and destitution (defined as falling into poverty). Following our earlier work in Decerf et al. [3], we have used years of human life (either lost to premature death or lived in poverty) as our unit of measurement.

Measuring the mortality burden in terms of years of life lost, we found that this burden increases systematically and markedly with per capita GDP. There were approximately one hundred times as many years of life lost per capita among the high- and upper-middle income countries that lost the most, as in a typical low-income country. This massive disparity was driven by the fact that Covid-19 kills older people disproportionately, and considerably larger fractions of the population are elderly in richer than in poorer countries. Higher residual life-expectancies among the elderly in richer countries also contributed.

The association between the poverty burden (measured in terms of additional years spent in poverty) and GDP per capita depends on how the poor are identified. Using a constant absolute poverty line such as the international (extreme) poverty line of \$1.90, the poverty burden is strongly negatively associated with GDP per capita. The world's poorest countries experienced poverty burdens between one hundred and one thousand times greater than the richest. However, when poverty lines typical of each of the four income categories (low income, lower middle-income, upper middle-income and high income) are used instead, that relationship effectively disappears.

Either way, the relative contribution of poverty (vis-à-vis mortality) to the aggregate welfare burden is much higher in poorer countries. In fact, the ratio declines systematically with GDP per capita across the whole range. This leads to an important first conclusion: the economic consequences of the pandemic in terms of increased poverty cannot be treated as being of secondary importance. Even at our most conservative rate for comparing life- and poverty-years (twenty of the latter to one of the former), there are 70 countries in our sample where poverty was a more important source of declining well-being than mortality. That number rises to 108 countries (three quarters of our sample) at the lower rate of five poverty-years to one life-year. Most (but not all) of those countries tend to be poor. They are not the countries where the medical and social scientists, the journalists and global civil servants that set the terms of the "global" public debate are located. The importance of the poverty consequences of the pandemic, relative to those of mortality, has not been given its proper weight in the global discussion.

Our second main conclusion relates to the distribution of the aggregate welfare burden across countries - and it is nuanced. We show that the association between the welfare burden and initial per capita incomes is not always unambiguously positive or negative. Instead, the shape of the relationship depends on two key factors: how poverty is defined, and the welfare weight placed on it relative to mortality. When poverty in a country is assessed in terms of poverty lines typical of countries at similar levels of development, a positive association arises: richer countries have suffered a greater loss in welfare than poor ones in this pandemic. That conclusion still holds even if the international extreme poverty line (IPL) is used instead, provided sufficient weight is placed on mortality relative to poverty. But if the IPL is combined with a lower welfare weight for death relative to destitution, the association reverses and poorer countries bear a greater welfare loss from the pandemic on average.

The fact that the association can be positive under plausible parameter configurations at all reflects once again the magnitude of the income gradient of Covid-mortality shown in Figure 1. Although this strong association between Covid-mortality and national income does reflect population age structures, including residual life-expectancies, it is important to note that demography is not destiny. Japan, by some measures the world's "oldest" country, suffered welfare losses orders of magnitude lower than Belgium, Germany and the US. China, South Korea, Norway and Australia did even better. This is probably one of those cases where the variation around the regression line matters more than the variation along it. That is the variation that reflects, among other things, differences in policy responses: the speed with which the virus was contained upon arrival, either by effective testing and tracing protocols or by early and wellenforced lockdowns, by early and widespread use of masks and social distancing, or some combination of the above. Our study has nothing to say about that fundamental source of variation.

\footnotetext{
${ }^{25}$ The fact that economic contractions were deeper in countries where the loss of life was greater is also consistent with the finding by Andersen and Gonzalez [16] that reductions in economic mobility (using data from Google's Community Mobility Reports) and the loss of life years were positively correlated across countries
} 
Four final caveats are warranted. First, and as noted earlier, our results are sensitive to measurement error. The possibility that Covid-related mortality is substantially under-estimated in many countries is of particular concern. If the underestimation is concentrated among poor countries, this could alter both of our main findings.

Second - and also noted earlier - we have used "aggregate" or "total" welfare loss as a shorthand for losses arising from mortality and entry into poverty. The pandemic has undoubtedly had other effects on well-being, both current and future; both among the sick and among those only indirectly affected.

Third, the pandemic is still ongoing, and the distribution of both the poverty and mortality burdens in 2021 may turn out to be very different from that of 2020 - particularly as access to vaccination is spreading unequally around the world. This could cause an eventual "post-pandemic" version of the global distribution of welfare losses to differ from all of those in our Figure 4, with poorer countries doing even worse.

Fourth, we have nothing to say on the important issue of how losses in well-being are distributed within countries. If, as seems likely, richer countries have been better able to cushion the losses among their poorer residents than poor countries have, it is quite possible that the world's very poorest people have suffered the most. An investigation of the distributional consequences within countries will be extremely important, but it will require post-pandemic household survey data and goes beyond the remit of this paper.

Despite these important caveats, our analysis does suggest that the poverty consequences of the pandemic should be given as much importance in the global policy conversation as its mortality consequences. For most poor and middleincome countries, greater economic deprivation has in fact been a more important source of loss in well-being than premature mortality. Ignoring the large welfare costs of destitution would lead us to the wrong conclusions about the distribution of the burden of the pandemic across countries, exaggerating the share of suffering visited on richer, older countries to the detriment of poorer ones.

\section{Additonal Files}

The additional files for this article can be found as follows:

- Appendix 1. Estimation procedure for the years of life lost to the pandemic in each country. DOI: https://doi. org/10.31389/lseppr.34.s1

- Appendix 2. Age-specific mortality estimates; share of the population over 65; and residual life-expectancies at 65 all correlate with GDP per capita. https://doi.org/10.31389/lseppr.34.s2

\section{Acknowledgements}

We are grateful to Lykke Andersen, Angus Deaton, Martin Ravallion, Andres Velasco and participants at the Lemann Center seminar at Stanford University for comments on an earlier version. All remaining errors are our own, as are all the views expressed.

\section{Competing Interests}

The authors have no competing interests to declare.

\section{Publisher's Note}

This paper underwent peer review using the Cross-Publisher COVID-19 Rapid Review Initiative.

\section{References}

1. World Bank. Global Economic Prospects, January 2021. Washington, DC: World Bank; 2021. Available from: https://openknowledge.worldbank.org/handle/10986/34710.

2. Lustig N, Neidhöfer G, Tommasi M. Short and Long-Run Distributional Impacts of COVID-19 in Latin America. Working Paper No. 2013. Tulane University, Department of Economics; 2020.

3. Decerf B, Ferreira FHG, Mahler DG, Sterck O. Lives and Livelihoods: Estimates of the Global Mortality and Poverty Effects of the COVID-19 Pandemic. Policy Research Working Paper 9277. Washington, DC: World Bank; 2020. DOI: https://doi.org/10.1596/1813-9450-9277

4. Viscusi WK. The value of risks to life and health. Journal of Economic Literature. 1993; 31(4): 1912-1946.

5. Becker GS, Philipson TJ, Soares RR. The quantity and quality of life and the evolution of world inequality. American Economic Review. 2005: 95(1): 277-291. DOI: https://doi.org/10.1257/0002828053828563

6. Adler MD, Bradley R, Ferranna M, Fleurbaey M, Hammitt J, Voorhoeve A. Assessing the wellbeing impacts of the Covid-19 pandemic and three policy types: Suppression, control, and uncontrolled spread. Saudi Arabia: Think20; 2020.

7. Dicker D, Nguyen G, Abate D, et al. Global, regional, and national age-sex-specifc mortality and life expectancy, 1950-2017: A systematic analysis for the global burden of disease study 2017. The Lancet. 2018; 392(10159):16841735. DOI: https://doi.org/10.1016/S0140-6736(18)31891-9

8. Deaton A. COVID-19 and global income inequality. National Bureau of Economic Research Working Paper. 28392; 2021. DOI: https://doi.org/10.3386/w28392 
9. Goldberg PK, Reed T. The effects of the coronavirus pandemic in emerging market and developing economies: An optimistic preliminary account. Brooking Papers on Economic Activity. 2020; 6(1). DOI: https://doi.org/10.1353/ eca.2020.0009

10. Lakner C, Mahler DG, Negre M, Prydz EB. How much does reducing inequality matter for global poverty? Global Poverty Monitoring Technical Note. 13; 2020. DOI: https://doi.org/10.1596/33902

11. Castaneda ARA, Mahler DG, Newhouse D. Nowcasting Global Poverty. Paper presented at the Special IARIWWorld Bank Conference. New Approaches to Defining and Measuring Poverty in a Growing World. Washington, DC, 2019 November 7-8.

12. Ferreira, FH, Chen S, Dabalen A, et al. A global count of the extreme poor in 2012: data issues, methodology and initial results. Journal of Economic Inequality. 2016; 14(2): 141-172. DOI: https://doi.org/10.1007/s10888-016-9326-6

13. Atkinson AB, Bourguignon F. Poverty and Inclusion from a World Perspective. In Stiglitz J, Muet PA, editors Governance, Equity and Global Markets. New York: Oxford University Press; 2001.

14. Ravallion M, Chen S. Weakly relative poverty. Review of Economics and Statistics. 2011; 93(4): 1251-1261. DOI: https://doi.org/10.1162/REST_a_00127

15. Jolliffe D, Prydz EB. Estimating international poverty lines from comparable national thresholds. Policy Research Working Paper 7606. Washington, DC; 2016. DOI: https://doi.org/10.1596/1813-9450-7606

16. Andersen LE, Gonzales Rocabado A. Life and Death during the First Year of the COVID-19 Pandemic: An analysis of cross-country differences in changes in quantity and quality of life. Latin American Journal of Economic Development. Forthcoming, May 2021; 35.

17. Salje, H, Kiem CT, Lefrancq N, Courtejoie N, Bosetti P, Paireau J, Andronico A, Hoze N, Richet JJ, Dubost CL, et al. Estimating the burden of sars-cov-2 in France. Science. 2020; 369(6500): 208-211. DOI: https://doi. org/10.1126/science.abc3517

18. Verity R, Okell LC, Dorigatti I, et al. Estimates of the severity of coronavirus disease 2019: A model-based analysis. The Lancet Infectious Diseases. 2020; 20(6): 669-677. DOI: https://doi.org/10.1016/S1473-3099(20)30243-7

19. Heuveline P, Tzen M. Beyond deaths per capita: comparative COVID-19 mortality indicators. BMJ Open. 2021; 11 : e042934. DOI: https://doi.org/10.1136/bmjopen-2020-042934

How to cite this article: Ferreira FHG, Sterck O, Mahler DG and Decerf B. Death and Destitution: The Global Distribution of Welfare Losses from the COVID-19 Pandemic. LSE Public Policy Review. 2021; 1(4): 2, pp.1-11. DOI: https://doi.org/10.31389/ Iseppr.34

Submitted: 15 February 2021

Accepted: 13 April 2021

Published: 03 May 2021

Copyright: ( $) 2021$ The Author(s). This is an open-access article distributed under the terms of the Creative Commons Attribution 4.0 International License (CC-BY 4.0), which permits unrestricted use, distribution, and reproduction in any medium, provided the original author and source are credited. See http://creativecommons.org/licenses/by/4.0/. 